\title{
Synergistic Anti-Tumor Effect of Cisplatin When Combined with an Anti-Src Kinase Integrin-Based Peptide
}

\author{
Michael Agrez ${ }^{1}$, Madhu Garg ${ }^{2,3}$, Douglas Dorahy ${ }^{3}$, Stephen Ackland ${ }^{2,3}$ \\ ${ }^{1}$ Division of Surgery, John Hunter Hospital, Newcastle, New South Wales, Australia; ${ }^{2}$ Department of Medical Oncology, Calvary \\ Mater Hospital, Waratah, New South Wales, Australia; ${ }^{3}$ Hunter Medical Research Institute, John Hunter Hospital, Newcastle, New \\ South Wales, Australia. \\ Email: michael.agrez@hnehealth.nsw.gov.au
}

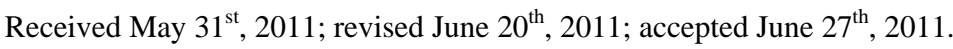

\begin{abstract}
Background: It is known that active Src kinase promotes survival of ovarian cancer cell lines and inhibition of c-Src has been shown to restore sensitivity of drug-resistant human ovarian cancer cells to cisplatin. In this study we examined the effects of a 10 mer peptide on proliferation of human colon and ovarian cancer cells when used alone and in combination with cisplatin. Materials and Methods: A 10 mer peptide, RSKAKNPLYR, derived from a 15 mer ERK2 binding sequence present on the cytoplasmic domain of the $\beta 6$ integrin subunit was tested for its effect on proliferation of HT29 colon cancer cells under serum-free conditions by means of the MTT assay. Cell proliferation studies to examine the effects of cisplatin combined with peptide were conducted in serum-containing medium using the 10 mer peptide fused to a hydrophobic signal peptide sequence. Drug combination studies were performed on HT29 cells and a cisplatin-resistant cell line (ADDP) derived from an ovarian cancer cell line A2780. The effects of peptides on Src kinase activity were assessed in a cell-free in vitro kinase assay. Results: The 10 mer peptide was as effective as the 15 mer parent compound at inhibiting proliferation of HT29 cells. Exposure of HT29 and ADDP cells to a combination of cisplatin and the fusion peptide resulted in synergistic inhibition of cell growth. Both the 10 mer peptide alone and when fused to the signal peptide sequence inhibited Src kinase activity. Conclusion: Our findings raise the possibility of combination therapy comprising peptide and cisplatin for cisplatin-resistant ovarian cancers and other cancers that are high expressors of $\mathrm{c}-\mathrm{Src}$.
\end{abstract}

Keywords: Cisplatin, Peptides, Cancer Cell Lines, MTT Assay, Synergy, C-Src

\section{Introduction}

Tumor chemotherapy with platinum-based compounds has met with mixed success. Cis-diamminedichloroplatinum (II)(cisplatin) is a long established anticancer drug with activity in a variety of solid tumor types including head and neck cancer, ovarian cancer and non-small cell lung cancer. However, major disadvantages of cisplatin include relapse in most tumors after an initial response [1] and the observed resistance to cisplatin as seen with colon cancer cells [2].

Inhibition of Src tyrosine kinase has been shown to enhance the cytotoxicity of cisplatin and restore sensitivity in drug-resistant cells [3]. Moreover, in colon cancer decreased Src expression in the cell line HT29 (that has high constitutive Src expression and activity) by means of antisense Src increases susceptibility of the cells to anoikis [4]. Conversely, the enforced expression of activated Src in the colon cancer cell line, SW480 (that has low intrinsic Src expression and activity) increases resistance of the cells to anoikis [4]. Src kinases are cellular homologues of the products of the Rous sarcoma virus gene (v-Src) which is the mutated and activated version of a normal cellular gene (c-Src). Src tyrosine kinase is the prototypical member of the Src family of cytoplasmic membrane-associated non-receptor tyrosine kinases and Src family members are critical mediators of multiple signaling pathways that regulate all stages of cancer progression. For example, Src family kinases are required for the endomembrane activation of the growthpromoting Ras-MAPK pathway where they phosphorylate and activate PLC-gamma1 leading to Ras activation 
[5].

C-Src activation has been documented in upwards of $50 \%$ of tumors derived from the colon, liver, lung, breast and pancreas [6,7]. C-Src activity increases with progressive stages of disease in colon cancer and is thought to be predictive of poor clinical prognosis suggesting that c-Src activation confers growth and/or survival advantages to metastatic colon tumor cells [8-10]. It has been postulated that c-Src activation may contribute to colon tumor progression and metastasis by activating Aktmediated survival pathways that decrease sensitivity of detached cells to anoikis [4]. C-Src has also been shown to be over-expressed and activated in a high proportion of ovarian cancers [11] and inhibition of c-Src sensitizes ovarian cancer cells to chemotherapeutic agents such as paclitaxel and cisplatin [3].

A functional interaction between activation of c-Src and integrins is well-recognised. Integrins comprise a family of cell adhesion receptors composed of alpha/beta heterodimeric subunits that provide a functional and structural bridge between the extracellular matrix and intracellular signaling molecules [12]. For example, it has been suggested that binding of the c-terminal portion of the cytoplasmic tail of the $\beta 3$ integrin subunit to the c-Src SH3 domain can disrupt the auto-inhibitory interactions between the SH3 and SH2 domains of Src [13].

Expression of the $\alpha \mathrm{v} \beta 6$ integrin in ovarian cancers may contribute to the invasive potential of ovarian cancers [14] and expression of the $\alpha \mathrm{v} \beta 6$ integrin in colon cancer has been identified as an independent prognostic indicator for worse outcome in patients suffering from this disease [15]. We have previously reported that a sequence of 15 amino acids, RSKAKWQTGTNPLYR, located within the cytoplasmic tail of the $\beta 6$ integrin subunit binds to extracellular signal-regulated kinase 2 (ERK2) and proposed that this contributes to tumor growth [16]. Moreover, a non-naturally occurring peptide, RSKAKNPLYR, derived from this binding sequence also binds with equal affinity to ERK2 [17]. In the present study we examined the effect of the 10 mer peptide on in vitro growth of human colon and ovarian cell lines in the absence and presence of cisplatin.

\section{Materials \& Methods}

\subsection{Cell Lines and Culture Conditions}

The human colon cancer cell line HT29, an ovarian cancer cell line, A2780, and its cisplatin resistant subline, ADDP, were used for the in vitro studies. The cisplatin-resistant cell subline, ADDP, was developed from long term exposure of the ovarian cancer cell line, A2780, to cisplatin [18] and both cell lines were obtained with kind permission from Dr G.J. Peters, Amsterdam, Neth- erlands [19]. Cell lines were cultured at $37^{\circ} \mathrm{C}$, under air containing $5 \% \mathrm{CO}_{2}$ and passaged regularly for optimal growth. Cells were maintained in DMEM medium containing $10 \%$ fetal bovine serum. All culture medium preparations were further supplemented with penicillin/ streptomycin $(100 \mu \mathrm{g} / \mathrm{ml})$, and glutamine (2 mM).

\subsection{Peptides}

All peptides were synthesized by Auspep, Melbourne, Australia. For cell growth assays performed in the presence of serum, the 10 mer RSKAKNPLYR, was linked at its amino terminus to a modification of the hydrophobic signal peptide from the Kaposi fibroblast growth factor, AAVALLPAVLLALLAP [20] that lacked the c-terminal proline (AAVALLPAVLLALLA) and the fused peptide was designated IK2 (AAVALPAVLLALLARSKAKNPLYR).

\subsection{In Vitro Growth Inhibition Assay}

Cells in logarithmic growth were transferred to 96-well plates in $100 \mu \mathrm{l}$ medium at a density of 2500 cells per well for serum-containing experiments and at a density of 4000 cells per well for serum free medium (SFM) experiments. For serum-containing experiments, $100 \mu \mathrm{l}$ medium with or without the test agent (50 $\mu$ l single agent with $50 \mu \mathrm{l}$ medium or $50 \mu \mathrm{l}$ of both agents for combination studies) were added to each well in triplicate 24 hours after plating, while for SFM experiments the previously added serum-containing medium was removed and $200 \mu \mathrm{l} \mathrm{SFM}$ medium with or without the test agent added to each of triplicate wells. Drug exposure experiments were carried out on cell lines using varying concentrations of agents: peptides (50 nM - $100 \mu \mathrm{M})$, cisplatin $(0.5 \mu \mathrm{M}-100 \mu \mathrm{M})$ as single agents, and for combination studies a fixed concentration of IK2 $(30 \mu \mathrm{M})$ was added to varying concentrations of cisplatin (in triplicate) for $48 \mathrm{hr}$ in serum-containing medium. For single agent peptide studies, cells were exposed to peptides for 72 - 96 hours in serum-free culture medium.

Growth-inhibitory effects were evaluated using the MTT (3-[4,5-dimethylthiazol-2-yl] 2,5-diphenyltetrazolium bromide) cell growth assay and absorbance read at $540 \mathrm{~nm}$. Growth of control cells was exponential during the whole incubation period. The growth inhibitory effect $\left(\mathrm{GI}_{50}\right)$, calculated as the drug concentration at which cell growth was inhibited by $50 \%$, was compared with untreated control cells and determined for both single agents and for peptide/cisplatin combinations for each cell line. Mean surviving fractions \pm SEM values (minimum of 3 separate experiments) were determined for each peptide/cisplatin concentration. The observed inhibitory effects on cell growth for peptide combined with cisplatin were compared with the calculated effects 
to be expected based on percentage inhibition of cell growth in the presence of peptide alone multiplied by the inhibition of cell proliferation for cisplatin alone at each concentration of cisplatin for both HT29 and ADDP cells (termed "additive" in the graphed data shown). Growth inhibition in compound combination studies that exceeded the calculated additive effect was indicative of a synergistic effect.

\subsection{C-Src Kinase Activity Assay}

In vitro c-Src kinase activity assays were performed by Upstate Kinase Profiling, Dundee, Scotland, according to the manufacturer's instructions. In brief, in a final reaction volume of $25 \mu \mathrm{L}$, c-Src (h) (5 mU - $10 \mathrm{mU})$ was incubated with $8 \mathrm{mM}$ MOPS $\mathrm{pH}$ 7.0, $0.2 \mathrm{mM}$ EDTA, $250 \mu \mathrm{M}$ KVEKIGEGTYGVVYK (Cdc2 peptide), 10 $\mathrm{mM}$ MgAcetate and [Y-33P-ATP] (specific activity approximately $500 \mathrm{cpm} / \mathrm{pmol}$ ). The reaction was initiated by the addition of the MgATP mix. After incubation for 40 minutes at room temperature, the reaction volume was stopped by the addition of $5 \mu \mathrm{L}$ of a $3 \%$ phosphoric acid solution. $10 \mu \mathrm{L}$ of the reaction volume was then spotted onto a P30 filtermat and washed three times for 5 minutes in $75 \mathrm{mM}$ phosphoric acid and once in methanol prior to drying and scintillation counting.

\section{Results}

The 10 mer peptide, RSKAKNPLYR, was as effective as the 15 mer parent compound RSKAKWQTGTNPLYR at inhibiting in vitro proliferation of HT29 cells cultured under serum-free conditions as shown in Figure 1, Panel A. Cleavage of amino acids from the amino terminus of RSKAKNPLYR in the presence of serum enzymes (unpublished data) accounts for its lack of effect in the presence of serum (see Figure 1, Panel B).

To enhance both metabolic stability and transmembrane transport, the active peptide was fused to the hydrophobic signal peptide sequence, AAVALLPAVLLALLA, derived from Kaposi's fibroblast growth factor [19]. As shown in Figure 1, Panel B, the anti-proliferative effect of RSKAKNPLYR on HT29 cells cultured in serumcontaining medium was restored when the 10 mer was fused with the signal peptide sequence (AAVALLPAVLLALLARSKAKNPLYR, designated IK2) and was not accounted for by effects of the signal peptide itself which was ineffective at inhibiting cell growth (Figure 1, Panel B).

Exposure of HT29 and ADDP cells to a combination of cisplatin and IK2 $(30 \mu \mathrm{M})$ resulted in synergistic inhibition of cell growth (thicker graphed lines for observed inhibition of cell growth shown in Figure 1, Panels C and $\mathrm{D}$, respectively). The observed values for growth inhibition at each cisplatin concentration in combined studies exceeded expected additive values at concentrations of cisplatin above $10 \mu \mathrm{M}$ for HT29 cells and $5 \mu \mathrm{M}$ for ADDP cells (Figure 1, Panels C and D, respectively). The selection of a fixed concentration of $30 \mu \mathrm{M}$ of IK2 in combination studies was based upon the approximate mean $\mathrm{GI}_{50}$ values for HT29 and ADDP cells in the presence of peptide alone as shown in Table $\mathbf{1 .}$

The $\mathrm{GI}_{50}$ values for cells cultured under serumcontaining and serum-free conditions in the presence of compounds alone and in combination are shown in Table 1. For ADDP cells, $\mathrm{GI}_{50}$ values for the combination of compounds exceeded the values for the calculated additive effect of cisplatin and IK2 alone (Table 1). However, for HT29 cells, the $\mathrm{GI}_{50}$ values for observed and additive effects for combination of compounds overlapped at lower concentrations of cisplatin and synergism was seen only at concentrations above $10 \mu \mathrm{M}$ of cisplatin. Notably, as seen in Figure 1, Panels B, C and D, the surviving fraction of cells exposed to IK2, IK2 plus cisplatin and cisplatin alone, respectively, goes below zero at higher concentrations indicating actual cell killing and not just growth arrest or inhibition. In cell-free in vitro kinase assays both the active peptide, RSKAKNPLYR, and the fusion peptide, IK2, inhibited Src kinase activity to the same degree (Figure 2).

\section{Discussion}

The c-Src oncogene is over-expressed and activated in a high proportion of ovarian cancers [11]. Accordingly, targeted therapy with the Src inhibitor dasatinib has been shown to interact in a synergistic manner with platinum-based chemotherapy in ovarian cancer cells [21]. A 15 mer peptide, RSKAKWQTGTNPLYR, representing the ERK2 binding sequence located within the $\beta 6$ integrin tail has previously been reported to also inhibit c-Src activity [22]. In the present report we show that a deletion variant of this peptide, RSKAKNPLYR, lacking the middle five amino acids (i.e., WQTGT) inhibits both c-Src activity as well as cancer cell growth in vitro. Moreover, the combination of this 10 mer peptide with cisplatin results in synergistic inhibition of proliferation of colon and ovarian cancer cells.

Although we have not specifically examined how readily the 10 mer peptide RSKAKNPLYR passes through cell membranes, a FITC-labeled multimer of this sequence is detectable within the nucleus of HT29 colon cancer cells within one hour of exposure to peptide (unpublished data). In the present study we coupled the 10 mer peptide to the cell-penetrating, hydrophobic signal peptide sequence derived from Kaposi's fibroblast growth factor [20]. As shown by these investigators this cell-permeable signal peptide sequence effectively ferries its functional cargo peptide across the plasma membrane 
HT29 Cells exposed to peptides in serum-free medium
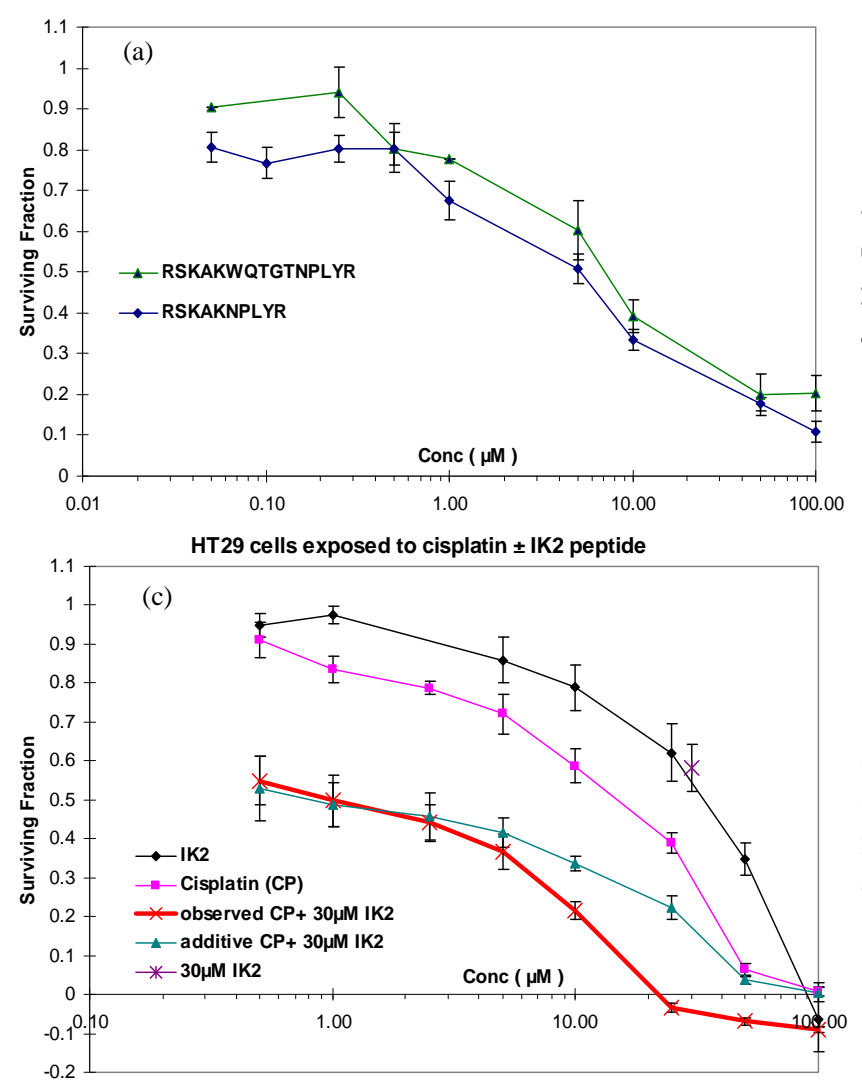

HT29 Cells exposed to peptides in serum-containing medium

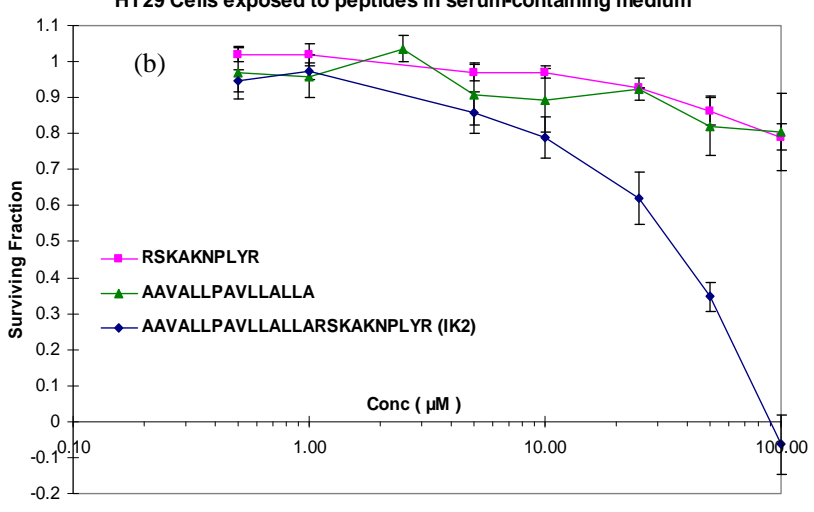

Ovarian cancer cell lines exposed to cisplatin \pm IK2 peptide

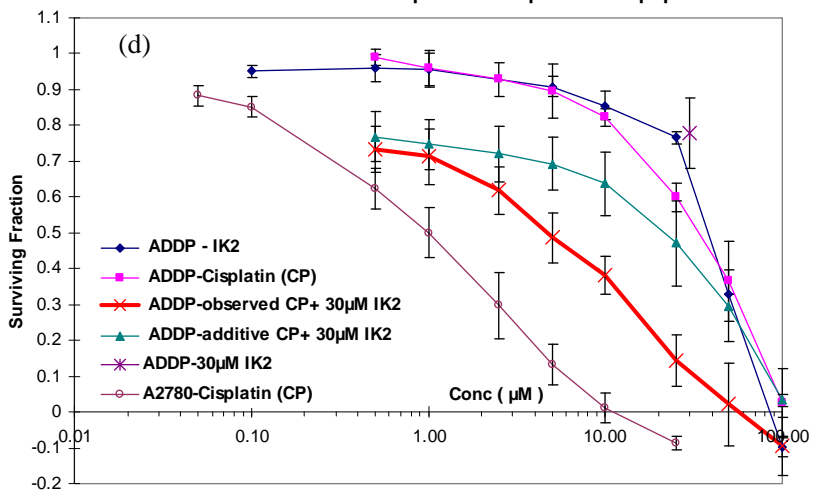

Figure 1. (a) Growth response curves for HT29 colon cancer cells cultured in the presence of peptides under serum-free conditions for 72 hours. (b) Growth response curves for HT29 cells cultured in the presence of peptides in serum-containing medium for 72 - 96 hours. (c) Growth response curves for HT29 cells cultured for 48 hours in the presence of either cisplatin or peptide alone and in combination using a fixed concentration of peptide, $30 \mu \mathrm{M}$. (d) Growth response curves for ovarian cancer cells cultured for 48 hours in the presence of either cisplatin alone (A2780 cell line that is cisplatin-sensitive and the ADDP cell line that is cisplatin resistant), peptide alone (ADDP cells) and in combination using a fixed concentration of peptide, $30 \mu M($ ADDP cells). Values are means \pm SEM.

Table 1. GI ${ }_{50}$ values (Mean \pm SEM) for cells cultured under serum-free and serum-containing medium exposed to single and combination of compounds.

\begin{tabular}{|c|c|c|c|c|}
\hline \multirow{4}{*}{$\begin{array}{l}\text { Serum- } \\
\text { free } \\
\text { medium }\end{array}$} & & \multicolumn{3}{|c|}{ Mean \pm SEM $(\mu M)$} \\
\hline & COMPOUNDS & HT29 & ADDP & A2780 \\
\hline & RSKAKNPLYR & $5.06 \pm 1.01$ & & \\
\hline & RSKAKWQTGTNPLYR & $6.33 \pm 2.18$ & & \\
\hline \multirow{4}{*}{$\begin{array}{l}\text { Serum- } \\
\text { cotaining } \\
\text { medium }\end{array}$} & $\begin{array}{l}\text { AAVALLPAVLLALLA-RSKAKNPLYR } \\
\text { (IK2) }\end{array}$ & $36.67 \pm 6.01$ & \multicolumn{2}{|c|}{$35.67 \pm 4.70$} \\
\hline & Cisplatin (CP) & $16.33 \pm 2.96$ & $34.50 \pm 4.38$ & $1.40 \pm 0.61$ \\
\hline & Observed CP + $30 \mu \mathrm{M}$ IK2 & & $6.83 \pm 3.65$ & \\
\hline & Additive CP + $30 \mu \mathrm{M}$ IK2 & & $28.33 \pm 8.82$ & \\
\hline
\end{tabular}

of mammalian cells [23]. This is consistent with our own unpublished observation that IK2 (signal peptide fused to RSKAKNPLYR) is 10-fold more effective at inhibiting proliferation of HT29 cells under serum-free culture conditions, i.e., in the absence of peptide-degrading enzymes, than the 10 mer sequence alone.
Cisplatin sensitivity has been reported to be reduced approximately 17-fold for the cisplatin-resistant subline, ADDP, compared with the parent cell line, A2780 [18]. Moreover, depending on duration of exposure to cisplatin the sensitivity of ADDP cells to cisplatin is reduced by 20-40 fold compared with A2780 cells [19]. However, 


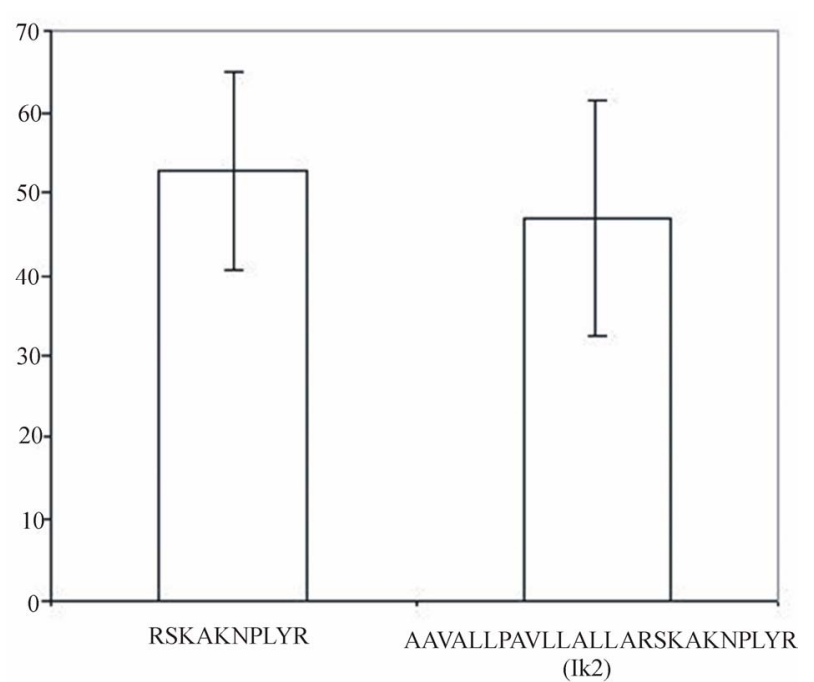

Figure 2. Percentage inhibition of c-Src kinase activity by peptides as determined by in vitro kinase assay. Values represent the mean percentage inhibition for three separate assays \pm SEM.

there are no published data on comparative levels of c-Src expression or activity between the cisplatinsensitive A2780 cell line and the cisplatin-resistant subline ADDP. Cisplatin-sensitive A2780 cells are known to be high expressors of Src [21] and whether Src deregulation is further enhanced in A2780 cells with acquired resistance to cisplatin such as the ADDP subline is not known.

The cause of clinical resistance to platinum compounds remains unknown and is likely to reflect a multi-factorial problem that is not exclusively related to increased c-Src activity or expression. For example, cisplatin-resistant ovarian cancer cells have been shown to be more effective at repairing cisplatin-DNA lesions and effluxing cisplatin or preventing influx of the drug $[24,25]$. Resistance to cisplatin has also been linked to expression of Stat1 (signal transducer and activator of transcription) in A2780 cells and to activation of the phosphatidylinositol 3-kinase (PI3K)/Akt signaling pathway in the ovarian cancer cell line OVCAR-3 $[26,27]$. Cell survival signals are mediated via PI3K/Akt and the tumor suppressor phosphatase and tensin homolog (PTEN) negatively regulates survival mediated by the PI3K/Akt pathway [28]. Interestingly, levels of PTEN in an A2780 subline with acquired resistance to cisplatin have been found to be lower than in the parental A2780 cell line [28]. Furthermore, the cellular response to cisplatin involves activation of multiple signal transduction pathways, including the mitogen-activated protein (MAP) kinase pathway [29]. For example, inhibition of cisplatin-induced ERK activation using the MAP/ERK kinase synthetic inhibitor PD98059 has been shown to enhance sensitivity to cisplatin in A2780 cisplatinsensitive and resistant cells [30].

We acknowledge several limitations of our study. Firstly, we have not shown that peptide-enhanced sensitivity to cisplatin in the A2780 cisplatin-resistant subline, ADDP, is a result of c-Src inhibition in these cells. Secondly, we cannot exclude the possibility that the 10 mer peptide derived from the ERK2 binding sequence on the cytoplasmic domain of the $\beta 6$ integrin subunit acts by inhibiting MAP kinase activation in ADDP cells in response to cisplatin. Moreover, whether or not the $10 \mathrm{mer}$ peptide inhibits upstream kinases involved in MAP kinase signaling remains to be determined by further in vitro kinase assays. Thirdly, we do not know whether the $\beta 6$ integrin cytoplasmic domain binds directly to c-Src. The 15 amino acid sequence on $\beta 6$ that has been reported to inhibit c-Src activity shares $53 \%$ - $60 \%$ homology with the $\beta 3$ and $\beta 5$ integrin cytoplasmic domains across that region [22]. Arias-Salgado and colleagues have recently shown in direct binding assays that the interaction between the GST-c-Src SH3 domain and the cytoplasmic tail of the $\beta 3$ integrin subunit required the four carboxyl-terminal residues [13]. Interestingly, this short amino acid sequence does not overlap with the homologous sequence on the cytoplasmic tail of the $\beta 6$ integrin subunit that inhibits c-Src activity.

Upon activation, c-Src is auto-phosphorylated at tyrosine residue 419 and phosphorylation of tyrosine 527 leads to an intra-molecular interaction between the $\mathrm{SH} 2$ and SH3 domains of c-Src that inhibits catalytic activity [31]. It has been suggested that binding of the c-terminal portion of the cytoplasmic tail of the $\beta 3$ integrin subunit to the c-Src SH3 domain can disrupt this auto-inhibitory interaction between the SH3 and SH2 domains of Src [13]. Possible mechanisms whereby integrin-derived peptides may interfere with this process include competition between peptide and integrin cytoplasmic domains for binding to c-Src or peptides themselves acting as intra-molecular ligands that engage both $\mathrm{SH} 2$ and SH3 domains, thereby, reducing Src activity [31].

Given the absence of a common driving oncogene in ovarian cancer the most promising treatment strategies are those that target drivers of tumorigenesis and enhance the activity of cytotoxic agents [32]. Drivers of tumorigenesis that have been proposed as relevant in ovarian cancer include receptor tyrosine kinases, non-receptor tyrosine kinases, serine/threonine kinases, transferases, proteases and deacetylases [32]. The non-receptor tyrosine kinase c-Src is an obvious therapeutic target in tumors exhibiting increased c-Src activity. Our findings raise the possibility of combining cisplatin with the peptide reported herein to treat cisplatin-resistant ovarian cancers and other cancers that are high expressors of 
c-Src.

\section{REFERENCES}

[1] K. J. Scanlon, M. Kashai-Sabet, T. Tone and T. Funato, “Cisplatin Resistance in Human Cancers," Pharmacology and Therapeutics, Vol. 52, No. 3, 1991, pp. 385-406. doi:10.1016/0163-7258(91)90033-I

[2] S. Huerta, D. M. Harris, A. Jazirehi, B. Bonavida, D. Elashoff, E. H. Livingston, et al., "Gene Expression Profile of Metastatic Colon Cancer Cells Resistant to Cisplatin-Induced Apoptosis," International Journal of Oncology, Vol. 22, No. 3, 2003, pp. 663-670.

[3] T. Chen, Y. Pengetnze and C. C. Taylor, "Src Inhibition Enhances Paclitaxel Cytotoxicity in Ovarian Cancer Cells by Caspase-9-independent Activation of Caspase-3,” Molecular Cancer Therapeutics, Vol. 4, No. 2, 2005, pp. 217-224.

[4] T. C. Windham, N. U. Parikh, D. R. Siwak, J. M. Summy, D. J. McConkey, A. J. Kraker, et al., "Src Activation Regulates Anoikis in Human Colon Tumor Cell Lines," Oncogene, Vol. 21, No. 51, 2002, pp. 7797-7807. doi:10.1038/sj.onc.1205989

[5] T. G. Bivona, I. P. De Castro, I. M. Ahearn, T. M. Grana, V. K. Chin, P. J. Lockyer, et al., "Phospholipase Cgamma Activates Ras on the Golgi Apparatus by Means of RasGRP1,” Nature, Vol. 424, 2003, pp. 694-698. doi:10.1038/nature01806

[6] S. C. Dehm and K. Bonham, "SRC Gene Expression in Human Cancer: The Role of Transcriptional Activation," Biochemistry and Cell Biology, Vol. 82, No. 2, 2004, pp. 263-274. doi:10.1139/003-077

[7] J. B. Bolen, A. Veillett, A. M. Schwartz, V. DeSeau and N. Rosen, "Activation of pp60c-src Protein Kinase Activity in Human Colon Carcinoma," Proceedings of the National Academy of Science USA, Vol. 84, No. 8, 1987, pp. 2251-2255. doi:10.1073/pnas.84.8.2251

[8] M. S. Talamonti, M. S. Roh, S. A. Curley and G. E. Gallick, "Increase in Activity and Level of pp60c-src in Progressive Stages of Human Colorectal Cancer,” Journal of Clinical Investigation, Vol. 91, No. 1, 1993, pp. 53-60. doi:10.1172/JCI116200

[9] P. M. Termulen, S. A. Curley, M. S. Talamonti, M. H. Saboorian and G. E. Gallick, "Site-Specific Differences in pp60c-src Activity in Human Colorectal Metastases," Journal of Surgical Research, Vol. 54, No. 4, 1993, pp. 293-298. doi:10.1006/jsre.1993.1046

[10] H. Aligayer, D. D. Boyd, M. M. Heiss, E. K. Abdalla, S. A. Curley and G. E. Gallick, "Activation of Src Kinase in Primary Colorectal Carcinoma: An Indicator of Poor Clinical Prognosis," Cancer, Vol. 94, No. 2, 2002, pp. 344-351. doi:10.1002/cncr.10221

[11] J. R. Weiner, T. C. Windham, V. C. Estrella, N. U. Parikh, P. F. Thall, M. T.Deavers, et al., "Activated SRC Protein Tyrosine Kinase is Overexpressed in Late-Stage Human Ovarian Cancers,” Gynecologic Oncology, Vol. 88, No. 1, 2003, pp. 73-79. doi:10.1006/gyno.2002.6851

[12] R. O. Hynes, “Integrins: Versatility, Modulation, and Sig- naling in Cell Adhesion,” Cell, Vol. 69, No. 1, 1992, pp. 11-25. doi:10.1016/0092-8674(92)90115-S

[13] E. G. Arias-Salgado, S. Lizano, S. Sarkar, J. S. Brugge, M. H. Ginsberg and S. J. Shattil, "Src Kinase Activation by Direct Interaction with the Integrin $\beta$ Cytoplasmic Domain," Proceedings of the National Academy of Science USA, Vol. 100, No. 23, 2003, pp. 13298-13302. doi:10.1073/pnas.2336149100

[14] N. Ahmed, F. Pansino, R. Clyde, P. Murthi, M. A. Quinn, G. E. Rice, et al., "Overexpression of $\alpha \mathrm{v} \beta 6$ Integrin in Serous Epithelial Ovarian Cancer Regulates Extracellular Matrix Degradation via the Plasminogen Activation Cascade," Carcinogenesis, Vol. 23, No. 2, 2001, pp. 237-244. doi:10.1093/carcin/23.2.237

[15] R. C. Bates, D. I. Bellovin, C. Brown, E. Maynard, B. Wu, H. Kawakatsu, et al., "Transcriptional Activation of Integrin $\beta 6$ during the Epithelial-Mesenchymal Transition Defines a Novel Prognostic Indicator of Agressive Colon Carcinoma,” Journal of Clinical Investigation, Vol. 115, No. 2, 2005, pp. 339-347.

[16] N. Ahmed, J. Niu, D. J. Dorahy, X. Gu, S. Andrews, C. J. Meldrum, et al., "Direct Integrin $\alpha \mathrm{v} \beta 6$ Binding: Implications for Tumour Growth,” Oncogene, Vol. 21, No. 9, 2002, pp. 1370-1380. doi:10.1038/sj.onc.1205286

[17] M. V. Agrez and N. Ahmed, "MAP Kinase IntegrinBinding Domain,” US Patent No. 7422883, 2008.

[18] Y. Lu, J. Han and K. J. Scanlon, "Biochemical and Molecular Properties of Cisplatin-Resistant A2780 Cells Grown in Folinic Acid,” Journal of Biological Chemistry, Vol. 263, No. 10, 1988, pp. 4891-4894.

[19] C. J. A. van Moorsel, H. M. Pinedo, H. M. Veerman, G. Bergman, A. M. Kuiper, J. B. Vermoken, et al., "Mechanisms of Synergism between Cisplatin and Gemcitabine in Ovarian and Non-Small-Cell Lung Cancer Cell Lines," British Journal of Cancer, Vol. 80, 1999, pp. 981-990. doi:10.1038/sj.bjc.6690452

[20] Y. Z. Lin, S. Y. Yao, R. A. Veach, T. R. Torgerson and J. Hawiger, "Inhibition of Nuclear Translocation of Transcription Factor NF-kappa B by a Synthetic Peptide Containing a Cell Membrane-Permeable Motif and Nuclear Localization Sequence,” Journal of Biological Chemistry, Vol. 270, 1995, pp. 14255-14258. doi:10.1074/jbc.270.24.14255

[21] D. Teoh, T. A. Ayeni, J. M. Rubatt, D. J. Adams, L. Grace, M. D. Starr, et al., "Dasatinib (BMS-35482) Has Synergistic Activity with Paclitaxel and Carboplatin in Ovarian Cancer Cells,” Gynecologic Oncology, Vol. 121, No. 1, 2011, pp. 187-192. doi:10.1016/j.ygyno.2010.11.017

[22] M. V. Agrez and D. J. Dorahy, "Inhibition of Multiple Activation Pathways,” International Patent Application, No. PCT AU2010/000203, 2010.

[23] R. A. Veach, D. Liu, S. Yao, Y. Chen, X. Y. Liu, S. Downs, et al., "Receptor/Transporter-Independent Targeting of Functional Peptides across Plasma Membranes," Journal of Biological Chemistry, Vol. 279, 2004, pp. 11425-11431. doi:10.1074/jbc.M311089200

[24] R. J. Parker, A. Eastman, F. Bostick-Bruton and E. Reed, 
“Acquired Cisplatin Resistance in Human Ovarian Cancer Cells is Associated with Enhanced Repair of Cisplatin-DNA Lesions and Reduced Drug Accumulation,” Journal of Clinical Investigation, Vol. 87, No. 3, 1991, pp. 772-777. doi:10.1172/JCI115080

[25] J. Helleman, H. Burger, I. H. Hamelers, A. W. Boersma, A. I. de Kroon, G. Stoter, et al., "Impaired Cisplatin Influx in an A2780 Mutant Cell Line: Evidence for a Putative, Cis-configuration-specific, Platinum Influx Transporter," Cancer Biology Therapy, Vol. 5, No. 8, 2006, pp. 943-949. doi:10.4161/cbt.5.8.2876

[26] D. Roberts, J. Schick, S. Conway, S. Biade, P. B. Laub, J. P. Stevenson, et al., "Identification of Genes Associated with Platinum Drug Sensitivity and Resistance in Human Ovarian Cancer Cells,” British Journal of Cancer, Vol. 92, 2005, pp. 1149-1158. doi:10.1038/sj.bjc.6602447

[27] S. Lee, E.-J. Choi, C. Jin and D.-H. Kim, “Activation of PI3K/Akt Pathway by PTEN Reduction and PIK3CA mRNA Amplification Contributes to Cisplatin Resistance in an Ovarian Cancer Cell Line,” Gynecologic Oncology, Vol. 97, No. 1, 2005, pp. 26-34. doi:10.1016/j.ygyno.2004.11.051

[28] C.-T. Lin, H.-C. Lai, H.-Y. Lee, W.-H. Lin, C.-C. Chang,
T.-Y. Chu, et al., "Valproic Acid Resensitizes CisplatinResistant Ovarian Cancer Cells,” Cancer Science, Vol. 99, No. 6, 2008, pp. 1218-1226. doi:10.1111/j.1349-7006.2008.00793.x

[29] A. Brozovic and M. Osmak, "Activation of Mitogen-Activated Protein Kinases by Cisplatin and Their Role in Cisplatin-Resistance,” Cancer Letters, Vol. 251, No. 1, 2007, pp. 1-16. doi:10.1016/j.canlet.2006.10.007

[30] W. Cui, E. M. Yazlovitskaya, M. S. Mayo, J. C. Pelling and D. L. Persons, "Cisplatin-Induced Response of c-Jun N-Terminal Kinase 1 and Extracellular Signal-Regulated Protein Kinases 1 and 2 in a Series of Cisplatin-Resistant Ovarian Carcinoma Cell Lines,” Molecular Carcinogenesis, Vol. 29, No. 4, 2000, pp. 219-228. doi:10.1002/1098-2744(200012)29:4<219::AID-MC1004 $>3.0 . \mathrm{CO} ; 2-\mathrm{D}$

[31] M. P. Playford and M. D. Schaller, "The Interplay between Src and Integrins in Normal and Tumor Biology," Oncogene, Vol. 23, 2004, pp. 7928-7946. doi:10.1038/sj.onc. 1208080

[32] K. M. Darcy and R. J. Schilder, "Relevant Molecular Markers and Targets,” Gynecologic Oncology, Vol. 103, No. 2, 2005, pp. 6-13. doi:10.1016/j.ygyno.2006.08.018 